\title{
Catalan adolescents' media uses and leisure preferences related to new media and television
}

\section{ABSTRACT}

This article presents the main findings of a Media Uses Study (MUS), carried out in Catalonia in the context of a wider study of adolescents' reception of television fiction programmes. Its main aim was to provide a general picture of Catalan adolescents' media uses and leisure preferences. Method included a survey of 239 adolescents aged 15 to 18, and three focus groups. Adolescents' media usage was characterized through the following elements: the weight of media-related activities within their leisure diet, the media equipment available, and the uses attributed by teenagers to the mobile phone, the Internet and television. Among the main results, the importance of the peer group in relation to both leisure and media activities must be emphasized. Moreover, adolescents' media usage can be described according to a double dynamics, with new media being used as tools for socializing and communication, and television especially for shared viewing with the family.

\section{KEYWORDS}

leisure

media

consumption

youth

adolescents

social relationships 


\section{INTRODUCTION}

In the current digital era, media consumption and leisure-related activities represent key aspects of daily life in contemporary western countries. The current so-called postmodern era is characterized by complex processes, phenomena and ways of thinking, such as globalization and media hybridization, the digital revolution and media convergence, consumer culture, the availability of commodities and the commercialization of leisure, among other features (e.g. Bauman 1997; Carlsson and von Feilitzen 2006; Ekström and Tufte 2007; Hill 2011; Martín-Guart and Fernández-Cavia 2012; Spigel and Olsson 2004). All these characteristics of our historical and social environment influence the way we act as human beings, as citizens, as consumers and as media users. This is especially true for adolescents, who were born and have grown up in a complex multimedia environment, within which they have to deal with the biological, psychological and social changes that characterize adolescence itself (Lee 2005; Livingstone and Bovill 2001; Maira and Soep 2004).

Indeed, nowadays teenagers have to cope not only with the complex changes typical of their age, but also with the constant transformations occurring in the current digital scenario. Nevertheless, current teenagers maintain a privileged relationship with the media environment and they often excel in media use. Media consumption is just one of the multiple leisure activities that adolescents have access to, since their physical, social and cultural environment is a multimedia and multi-screen one. Current generations of young people usually display multitasking and multimedia consumption patterns, and are increasingly more autonomous and independent from the rest of the family and more and more habituated to a sort of bedroom culture, particularly in relation to their media consumption (Adriaens et al. 2011; Brasel and Gips 2011; Drotner 2000; Jordan et al. 2007; Livingstone and Bovill 2001; Roberts and Foehr 2008; Vanderwater and Lee 2009). The bedroom culture phenomenon refers to the variety of media equipment young people, especially in western countries, have access to in their private spaces, such as their bedrooms, which are more and more similar to 'multiple-media environments' (Jordan et al. 2007) or 'media centers' (Zanker and Lealand 2006). According to Livingstone and Bovill (2001: 179-80), 'to many children across Europe and North America [...], this mediatic bedroom culture represents a vital yet takenfor-granted aspect of their daily lives that significantly enriches the variety of leisure opportunities open to them'. At any rate, some differences among countries do exist, since the extent to which the current scenario affects 'young people within each country depends on their respective welfare regimes' (Serracant 2012: 161). For instance, Mediterranean European countries' specific characteristics, like those of Spain or Catalonia, can generate different media usage compared to Northern European countries. In this matter, EU Kids Online Project pointed out that the Internet 'usage is highest in the Nordic countries and lowest in Southern Europe' (Livingstone et al. 2011: 12). On the other hand, delving into young people's specific media uses could also provide evidence of some similarities between different regions, since young people seem to share a common youth consumer and mass media culture on a global scale (Ekström and Tufte 2007).

Bearing this in mind, we carried out a Media Uses Study (MUS) in the context of a wider research project about adolescents' reception of television fiction programmes conducted in Catalonia. The wider project aimed 
for deeper study of the Catalan case mainly for three reasons. First, it was intended to contribute to knowledge about adolescents' consumption of television in Spain, since previous studies had focused on the populations of other Spanish regions, e.g. the Basque Country (Aierbe and Medrano-Samaniego 2008; Ramírez de la Piscina et al. 2006), the Madrid region (Montero-Rivero 2005), Aragon (Sabes-Turmo 2005) or Andalusia (Pindado 2006). Second, the research aimed to compare Catalan adolescents' media habits and preferences to those of other Spanish teenagers. Finally, Catalonia was expected to be a good case study to be compared to other Mediterranean regions or Southern European countries.

The main aim of the MUS was to provide a general and quite detailed picture of Catalan youth's media uses, in order to better understand their consumption of television fiction programmes within the rest of their media and leisure activities.

Furthermore, the MUS was guided by the following specific objectives:

- To describe the main traits of Catalan adolescents' media usage in the context of their leisure activities, identifying their favourite leisure activities and their media equipment.

- To identify the uses that Catalan adolescents attribute to different media, emphasizing differences or complementarities between their use of traditional media (i.e. TV) and new media (i.e. the mobile phone and the Internet).

- To compare Catalan adolescents' leisure and media diets to those of other young collectives, based on previous studies carried out in other countries.

- To contribute to knowledge of adolescents' leisure activities and preferences from the perspective of research in communication and media.

\section{YOUNG PEOPLE'S MEDIA USAGE AND LEISURE PREFERENCES}

Young people's typologies of media consumption and leisure time have been evolving over the last two decades, due to the new media context and the technological innovations mentioned above.

Data from the 1990s already stressed that teenagers in western countries had plenty of free time, which they usually spent watching television and socializing. In particular, Larson and Seepersad (2003: 53) compared data about American, European and East Asian adolescents and recognized that American teenagers had 'more free time than adolescents in most other industrial nations', and that they spent most of it 'in unstructured activities'. More specifically, American adolescents' most common leisure activities were: peer interactions, watching television, listening to music, playing games, computer and Internet use, and organized youth activities (like sports).

Flammer and Schaffner (2003) compared available data on European teenagers, pointing out the cultural differences between European countries, which affect adolescents' leisure diets. However, these authors show that European teenagers' most common leisure activities are electronic media use (such as watching television, listening to the radio or using computers), spending time with friends and dating, and doing sports.

Both reports describe the Internet and computer use as an emerging and increasing activity among young people. In fact, more recent works, carried out since the last years of the 1990s, have identified the main features of 
youth's media and leisure habits, emphasizing in particular their use of new media (e.g., Athenstaedt et al. 2009; Bell and Dittmar 2011; Coatsworth et al. 2005; Hagen 2007; Holloway and Green 2008; Livingstone et al. 2011; Pascoe 2011; Roberts and Foehr 2008; Romer et al. 2012; Thulin and Vilhelmson 2007; Videnović et al. 2010; Wilska and Pedrozo 2007).

When analysing previous research, several main findings can be pointed out:

In the first place, leisure and media diets depend on the cultural context, even if it is possible to identify some general traits in media habits and preferences of adolescents living in western and industrialized countries, such as similarities in their consumer and media culture, as mentioned above (Ekström and Tufte 2007). Teenagers' most common leisure activities generally are socializing or social activities, media consumption or use, sport activities, instrumental activities (such as academic school activities and paid work), and artistic activities (such as drama, choir, band, sculpting).

Second, gender differences can usually be found in regard to leisure activities: socializing and culture/education activities are generally more associated with girls, while sport and 'maladjusted' activities, such as smoking, drinking alcohol or consuming illegal drugs (Athenstaedt et al. 2009), tend to be more related to boys. Besides, gender is also a differentiating trait in adolescents' media diet, boys usually being more inclined to use more new media than girls (Grimley and Allan 2010; Livingstone and Helsper 2007).

Third, the importance of the peer group and socializing in adolescents' everyday life and leisure preferences must be emphasized. If they can choose what to do in their leisure time, teenagers generally prefer to spend time with their friends (Larson and Seepersad 2003; Roberts and Foehr 2008). Given this, media consumption itself can be considered as a socialization tool: media contents can be shared by the peer group, and they can also be a source of conversation among friends.

At any rate, media consumption represents one of young people's main leisure activities, but not the only one. They mostly spend time with electronic media, especially the Internet and television. Moreover, the great diffusion of mobile phones in this age group must be emphasized. In particular, young people tend to be 'very heavy texters or text message addicts' (IBBT 2011: 45).

Finally, it must be taken into account that young people consume or use several media simultaneously, performing what has been called a multimedia and multitasking media use (Brasel and Gips 2011; Drotner 2000; Ekström and Tufte 2007; Jordan et al. 2007). In particular, adolescents' uses of television and the Internet are often related and complementary, as FernándezPlanells and Figueras-Maz (2012) point out.

Teenagers are the target who spend the least time watching television, and as television consumption decreases, Internet use increases. This can be observed by comparing data for different years. Roberts and Foehr (2008) offer data for 2004, pointing out that adolescents usually spend most free time watching TV (2: 36 hours), consuming audio (2: 24 hours), and using the computer (1: 22 hours). More recent data, such as those in Bell and Dittmar (2011), point out that adolescents' Internet use is higher than that of any other media, closely followed by television and music videos.

Similarly, according to recent EU data, $87 \%$ of young people aged 16 to 24 use the Internet daily and $96 \%$ of them do so weekly, while $75 \%$ of young people watch television daily and $92 \%$ of them do so weekly (Eurobarometer 2013). According to the European study EU Kids Online mentioned above, 60\% of European children aged 9 to 16, and $80 \%$ of older teenagers aged 15 to 16 
go online daily, spending an average time of 88 minutes per day (Livingstone et al. 2011). In particular, teenagers aged 15 to 16 spend 118 minutes online per day, which is twice as long as 9-10-year-olds.

Moreover, this study classifies Spain as a 'lower use' country, since the average time spent online by Spanish children aged 9 to 16 is just 71 minutes per day. Similar data regarding young people's leisure habits and media habits have been obtained by other research and statistical studies carried out in Spain and Catalonia (e.g., Estudio General de Medios 2007; Funes 2008; INE 2012). In particular, according to EGM Baròmetre (2014), 87\% of Catalan young people aged 14 to 19 have access to the Internet and $85 \%$ of them have access to television.

On the other hand, several studies have demonstrated that television is still a social family media (Kortii 2011) for many adolescents, even if its consumption has also been an individual practice (Livingstone 2009). In particular, teens' television consumption becomes more independent from the rest of the family and tends to be more associated with their own bedrooms as they grow up (Livingstone and Bovill 2001). Besides, even if other home spaces are increasingly dedicated to different forms of screen consumption, and 'despite the availability of multiple television sets, the main television set still has great appeal to everyone in the house as the "first choice" television', precisely because it is the largest or the latest model and is usually positioned in the most comfortable position (Holloway and Green 2008: 50). Moreover, watching television in the living room often offers teenagers the opportunity to share social interaction and television-centred communication with the rest of the family (Adriaens et al. 2011).

Of course the Internet also offers television and audio-visual contents to young people. For this reason, even if their consumption of 'traditional television' is decreasing, their cross-media consumption of television contents must be taken into account.

\section{ADOLESCENTS AS ACTIVE AUDIENCES AND MEDIA USERS}

The MUS was carried out within the theoretical framework of cultural studies and audience studies, incorporating Uses and Gratifications Theory (Katz et al. 1974).

In particular, several concepts from this theoretical framework were taken into account: the concept of the active audience, the importance of the reception situation, and the idea of individual and social uses that audiences can make of mass media (e.g., Lull 1980; McQuail 1997; Morley 1986; Silverstone 1994).

First, we applied the concept of the active audience, that is an audience capable of understanding, decoding and interpreting media texts (e.g., Fiske 1987; Hall 1999; McQuail 1997), to current teenagers, who are active and frequent users of traditional and new media (Arnett et al. 1995).

Second, we stressed the concept of media uses, which is strictly related to the idea of the social functions of media. According to this idea, media can be consumed and used by audiences to respond to several needs, gratifications or functions, such as diversion or entertainment, social relationships or social contact, personal identity and values, getting information or learning about life and society, escaping from routine, structuring everyday life, sharing media consumption or contents, or socializing (Katz et al. 1974; McQuail et al. 1972; McQuail 1997). 
1. Quotes from the focus groups are identified according to the following scheme: FG (=Focus Group) + Number of focus group (1 for fourth year middle school, 2 for first year high school, or 3 for second year high school) $+\mathrm{g}(=\mathrm{girl})$ or b (=boy) + Number of participant (1 to 4 for girls and for boys) (age of participant).

2. We had to discard six incomplete ones.
Third, media use and consumption is generally influenced by, and related to, home, family and daily routines, including leisure activities and, above all, the peer group (Escardibul et al. 2013). For this reason, the specific reception situations of adolescents, as well as their spare time habits need to be taken into account in order to investigate their media usage.

\section{METHOD}

The wider research project including the MUS consisted of a reception study carried out through both quantitative and qualitative techniques in 2010.

In order to select the sample, all middle and high schools in Barcelona were contacted by e-mail, and finally two public schools and two private ones located in different neighbourhoods of the city were chosen among the ones interested in participating in the study.

The quantitative phase consisted of an online survey, administered to 239 middle and high school students from the four schools selected. Data were codified and analysed with SPSS software, using the $\chi^{2}$ test, the MannWhitney test or the Kruskal-Wallis test according to the kind of variable analysed to determine any dependency relation between variables (statistical significance set at $p \leq 0.05$ ). The questionnaire included closed and open-ended questions about adolescents' leisure preferences, media uses and fiction consumption habits.

The qualitative phase consisted of three focus groups ${ }^{1}$ of eight participants each (four girls and four boys). Focus groups were audio recorded, then transcribed and analysed with Atlas.ti software. During the qualitative phase we explored some of the main issues that arose in the quantitative phase, e.g. media functions, family relationships and adolescents' preferences and motivations.

The final sample consisted of $233^{2}$ middle and high school students, aged 15 to $18(x=15.98$, mode $=16)$. A total of $55.4 \%(n=129)$ were girls and $44.6 \%$ $(n=104)$ were boys. In particular, we analysed three middle adolescence age groups (http://www.unicef.org/adolescence), from three different school years: the fourth year of ESO (the Spanish compulsory middle school), when teenagers are 15-16 years old, the first year of Bachillerato (the Spanish noncompulsory high school), when teenagers are 16-17 years old, and the second year of Bachillerato, when they are 17-18 years old.

Participants in the focus groups were selected from the survey sample according to the following variables: gender, age (according to the school year), and media habits in terms of television consumption (heavy or soft consumers) and television fiction preferences (local or foreign programmes). Most of the teenagers in our sample were born in Catalonia $(68.2 \%, n=159)$, a very small part was born in other regions of Spain or in Europe $(3 \%, n=7)$, while the rest came from other continents, especially from South America and Central America (19.3\%, $n=45) .95 .3 \% \quad(n=221)$ of the sample were living in Barcelona city, most of them in a traditional family $(66.5 \%, n=155)$, that is a family made up by two parents and one or more siblings. Most of the young people in the sample had one or more siblings $(86.7 \%, n=202)$ and their families were mostly constituted by four or five members $(65.7 \%$, $n=153)$.

Most of the teenagers' parents had high school or university degrees, and half of them worked in white collar positions, such as managers, executives, public servants and private employment. 
We used Euromonitor's typology of television macrogenres and genres (Prado et al. 2012) to classify the television programmes indicated by respondents.

\section{RESULTS}

Main results of the MUS can be divided into the following three areas: (1) adolescents' media usage among their leisure preferences, (2) adolescents' media equipment, (3) adolescents' uses of three specific media: the mobile phone, the Internet and television.

\section{Adolescents' media usage within their leisure preferences}

In the first part of the questionnaire, we asked adolescents to indicate if they performed several recreational activities, in order to identify the weight of media in their leisure diet.

In adolescents' top five leisure preferences, there were at least three activities directly related to media usage: 'browsing the Internet' $(97.9 \%, n=228)$, 'listening to music' (97.9\%, n=228), and 'watching TV' (96.1\%), with 'socializing with the peer group' as our sample's favourite activity $(99.1 \%, n=231)$. The label 'watching TV' refers to television consumption through the television set, which does not exclude the possibility of young people consuming television contents also through other media or screens, while 'relating to friends' could include both face-to-face and mediated interactions.

The data can be analysed in depth if we take into account the frequency with which adolescents claimed to carry out the different leisure activities (always, often, sometimes, never). In fact, if we consider the highest frequencies (always and often), we can classify teens' favourite leisure activities into three levels:

- On the first level we can find those activities that were 'always' carried out in their free time by more than $40 \%$ of the sample, and 'always or often' by more than $80 \%$ of teens: relating to friends, browsing the Internet, and listening to music.

- On a second level, there are those activities that more than $50 \%$ of the sample claimed to 'always or often' do in their spare time, such as watching TV, relating with family, and playing sports.

- Finally, on a third level, is the rest of the activities, which most teenagers practiced 'sometimes', such as resting, reading, or doing artistic activities.

We also asked teenagers whom they usually spent their spare time with. Once again, we found that friends were their first choice: in fact almost the totality of our sample $(98.3 \%, n=229)$ claimed to spend their free time with friends at least sometimes, while $82.8 \%(n=193)$ said they 'always' or 'often' did so. On the other hand, the company of family members such as parents or siblings was not as frequent as that of the peer group. $53.6 \%(n=125)$ of teenagers claimed to spend their spare time with their parents only sometimes, and $42.5 \%(n=99)$ said the same regarding their siblings. Even less common was spending free time by themselves or with others, who generally could be other relatives, such as grandparents or cousins. In fact, some of the younger people in our sample had to spend the afternoon at other 
relatives' until their parents returned home from work, as the following examples illustrate:

FG3b3 (15 years old): I don't spend much time at home ... in the afternoon I usually stay at my cousins' $\ldots$... And I play with them.

FG3g3 (15 years old): (I cannot always watch what I want on TV) because I usually go to have lunch at my grandmother's and she puts on those kinds of programmes ...

Finally, we found some gender differences in teenagers' leisure preferences. Certain activities, such as shopping $(p<0.001)$, listening to music $(p=0.001)$ or artistic activities $(p<0.001)$ were most often practiced by the girls, while sport $(p<0.001)$ and playing video games $(p<0.001)$ were practiced more often by boys. On the other hand, there was no difference between genders in terms of their preference for socializing or in the use of the three media analysed in our study.

\section{Adolescents' media equipment}

We also asked participants to tell us about the kind of media equipment available at home and in their personal space (e.g., bedroom).

Teenagers in our sample had multiple media available in domestic and common spaces, with the television set as the most common media device present at home. Once again, we can identify three levels of media devices present in domestic and common spaces:

- The first level includes those media devices present in more than $90 \%$ of households, such as the television set $(99.1 \%, n=231)$, the mobile phone $(94.8 \%, n=221)$, the photo/video camera $(94.8 \%, n=221)$, the DVD player/ recorder $(94.4 \%, n=220)$, the computer in both laptop and desktop version $(91.8 \%, n=214)$, the landline $(90.6 \%, n=211)$, and MP3/MP4 player $(90.1 \%$, $n=210)$.

- The second level includes those media devices that were present in more than half of households, but did not reach a presence as high as the first level ones, e.g. video game console $(72.5 \%, n=169)$, handheld game console $(63.5 \%, n=148)$, or digital recorder $(54.5 \%, n=127)$.

- Finally, the last level includes those devices which had a lower presence, as they were present in less than half of households: the home cinema $(46.8 \%, n=109)$, and PDA $(26.6 \%, n=62)$.

On the other hand, the media equipment in adolescents' personal space was quite different from that of the rest of the household.

According to the same criteria used for classifying the home media environment, we can also identity three levels in the media equipment in teens' personal space:

- The first level includes the computer $(68.2 \%, n=159)$ and Internet access $(62.7 \%, n=146)$, which in most cases also included a Wi-Fi connection $(54.9 \%, n=128)$. The data on computer and Internet availability can be related to the European research mentioned above, which found that $67 \%$ of older children (15-16 years old) used the Internet in their bedroom (Livingstone et al. 2011). 
- At lower positions we can find media devices available in less than onethird of the adolescents' personal spaces, such as the television set (32.2\%, $n=75)$, the video game console $(29.2 \%, n=68)$, the DVD player $(22.3 \%$, $n=52)$, and the landline $(20.2 \%, n=47)$.

- The last level includes media devices present in less than $10 \%$ of cases, such as the digital recorder $(7.7 \%, n=18)$, the $\operatorname{VCR}(7.7 \%, n=18)$, and the home cinema $(5.6 \%, n=13)$.

Even if less than one-third of the sample had a television set in their personal spaces, it was quite common for them to have access to a second television set in other domestic spaces, including the kitchen or the parents' bedroom. So, if they wanted to, they could generally go and use another television set:

FG1g1 (15 years old): [...] if they are watching football, you go to another TV! [...] at home we usually have a TV assigned to each one of us. For example, my dad, after dinner, stays in the dining room, at the TV over there. But I go to my bedroom. My brother goes to the office, and my mom and my sister go to bed, so there is no problem at all.

FG1b4 (15 years old): You're lucky. (He smiles). [...] We are always fighting!

They laugh.

Researcher: And if you want to watch something that you like?

FG1b4 (15 years old): Well ... we go to the other TV, because we have two.

FG1g3: Yes. But there are times when my dad is in the living room, and my mom in their bedroom. So I have to stay with my dad, watching something that I'm really not interested in, or with my mom, and I'm not interested in what she's watching either.

\section{Adolescents' media uses}

\section{Adolescents' uses of the mobile phone}

Starting with the mobile phone, we must emphasize its great ubiquity among this age group. Either they had their own personal mobile phone, or had access to one (e.g., their parents').

We asked adolescents to state which mobile phone services they used at least sometimes. We found that the top activities teens used the mobile phone for were calling friends $(97.4 \%, n=227)$ or family $(95.2 \%, n=222)$ and sending/ receiving SMS (95.3\%, $n=223)$. On the other hand, while uses like taking photos or listening to music were quite frequent among adolescents in our sample (88.4\%, $n=206$ and 83.7\%, $n=195$, respectively), other multimedia activities, such as browsing the Internet or watching television programmes were more marginal $(24.1 \%, n=57$, and $9.9 \%, n=23$, respectively). Nevertheless, about $10 \%$ of the sample claiming to watch television programmes on the mobile phone at least sometimes could be considered as a signal of new television consumption habits. This tendency needs to be investigated more in-depth, especially taking into account the current penetration of smart phones.

Finally, it has to be emphasized that girls used the mobile phone more than boys for socializing, like calling friends $(p<0.001)$ and sending/receiving SMS $(p<0.001)$. 
Adolescents' uses of the Internet

In the second instance, we found that almost all teenagers in our sample had access to a computer and nearly a half of the sample had a laptop for personal use exclusively $(46.4 \%, n=108)$. Furthermore, computer access was generally associated with Internet access $(p<0.001)$. Indeed, the most frequent use that teenagers assigned to the computer was browsing the Internet $(x=7.8$, $\mathrm{SD}=2.44)$.

We also asked adolescents to mark on a ten-point scale which Internet uses they spent more time on. Results obtained show their special predilection for socializing and communicating activities, such as chatting $(x=7.94, \mathrm{SD}=2.749)$, e-mailing $(x=6.62, \mathrm{SD}=2.502)$, and sharing contents $(x=6.61, \mathrm{SD}=3.171)$. Other activities which obtained high scores were: downloading audio files ( $x=7.01$, $\mathrm{SD}=2.789)$, looking for information $(x=5.93, \mathrm{SD}=2.329)$, and studying ( $x=5.58$, $\mathrm{SD}=2.409$ ). Consuming audio-visual contents through the Internet, such as movies or television programmes, was not so well marked by teenagers in our sample, obtaining average scores lower than 5 .

Nevertheless, during the focus groups, we found out that adolescents in our sample often watched television contents online, especially music videos and segments of humour shows on YouTube:

FG2b3 (16 years old): When I'm bored ... like at the weekend when I don't have anything to do ... or in the afternoon, so I go and watch videos on YouTube, like Crakòvia ${ }^{3}$. Not the whole programme, just the part you're interested in!

FG2g1 (16 years old): I look for songs ...

FG2b1 (16 years old): ...or people getting hurt ...

Researcher: Do you share these videos with each other?

FG2b1 (16 years old): Yes, you put them on Facebook ...

Researcher: And do you watch these videos in the company of your friends?

FG2b1 (16 years old): Yes, sometimes.

FG2b3 (16 years old): To show them, yeah ... 'Have you seen that video?', and if they haven't, you show them.

Furthermore, in the second phase of the study of adolescents' television fiction consumption habits, our respondents responded that they also watched television fiction programmes on the Internet (Fedele et al. 2014).

The Internet usage and the television consumption must be related also in terms of time spent with each medium. In fact, young people in our sample claimed they usually spent more time surfing the Internet than watching television. For instance, on weekdays, $30.9 \%(n=72)$ of our sample spent more than two hours watching television, and 39.9\% ( $n=98)$ browsing the Internet, while at the weekend those percentages went up to $52.5 \%(n=122)$ and $58 \%$ $(n=146)$ respectively.

Finally we observed a gender difference, since the boys spent more time than girls looking for information $(p=0.02)$ and playing $(p<0.001)$, while girls spent more time than boys sharing contents $(p<0.001)$. 


\section{Adolescents' uses of television}

Adolescents in our sample usually watched television during the prime-time and the night slot (21.00-24.00), especially on weekdays, when television consumption tended to be concentrated at night and, second, in the afternoon (16: 00-21: 00). ${ }^{4}$ At weekends, however, television consumption was distributed more homogeneously among several programming slots.

Teenagers in our study mostly watched television at home in common spaces $(96.6 \%, n=225)$, shared with the rest of the family, especially during dinner, as they pointed out during the focus groups. In particular they used the living room, where the main television set is generally situated. Moreover, as pointed out above, even if most of our sample did not have a television set in their personal spaces, they could usually use another television set available in the household.

On the other hand, the main television preferences of young people in our sample can be related especially to entertainment, with Fiction and Info show as their favourite television macrogenres, with $53.5 \%(n=125)$ and $20.9 \%(n=49)$ of preferences respectively, followed by Show $(7.5 \%, n=17)$, Sport $(4.8 \%, n=11)$, Information $(4.8 \%, n=11)$ and other contents $(2.8 \%$, $n=7) .{ }^{5}$ Furthermore, participants in our study claimed to have enough freedom to choose what they wanted to watch on TV:

FG1b3 (15 years old): I usually decide what to watch, because my mum doesn't really like TV, so she is not interested in what I put on ...

FG1g1 (16 years old): I'm quite free. Well, we also have more than one TV set, and my mother usually doesn't watch TV, so ... I can really choose.

Despite this, sometimes teenagers had to reach an agreement with the rest of the family:

FG1b2 (16 years old): It depends. If you are alone at home, you can watch whatever you want. But if somebody else is there ... you must reach an agreement ... And if not, I watch what they choose or I turn on the computer...

FG1b1 (16 years old): Generally we do decide, my sister and I, because we know better what's on TV. But my parents can decide a lot, too.

Younger teenagers usually had to let others choose the programme more often than the older ones because their parents and siblings tended to monopolize the television set:

FG3g2 (15 years old): I usually watch Disney Channel because my little sister is watching it ... so I watch it too.

FG3g4 (15 years old): Of course I put on what I want to watch, but then ... my brother comes and he changes the channel ... (They laugh) $\mathrm{He}$ is younger than me, but ...he is the one who decides! (They laugh again).

At the same time, we found that older teens had more freedom than the younger ones to use the main television set by themselves:

FG2g1 (17 years old): My mum's schedule and mine generally don't coincide ... So I can watch television in the afternoon while she
4. Differently from Northern countries, the Mediterranean pre-dinner time can be considered still as the afternoon by Catalan young people.

5. $N A=5.7 \%(N=13)$ 
is working $[\ldots]$ yes, we only have one television set in the dining room.

FG2b2 (17 years old): I have only one television set too, so when I watch some series and my mum is not interested in them, she generally goes to her bedroom to read a book.

Many adolescents also watched television outside of their households, at friends' or other relatives' or in bars, for example, but with a low frequency. Bars were normally preferred by boys who wanted to watch football matches on pay TV channels not available at home. Other relatives' homes, such as cousins' or grandparents', were especially associated with younger adolescents, while friends' houses were more related to older teenagers $(p=0.028)$.

We also detected a sort of multitasking use of television carried out by young people in our sample, as they usually performed other activities while watching television. These simultaneous activities must be related with the most common leisure activities mentioned above, especially those related to socialization.

In fact, the two activities that teenagers performed most frequently while watching television were eating and talking to people (Figure 1). Indeed, these activities were carried out especially 'always or often' (eating: 76\%, $n=177$; talking: $65.3 \%, n=152$ ). Additionally, as mentioned before, we found during the qualitative phase that watching television during family meals was a common behaviour.

However, most of the sample reported that they only 'sometimes' carried out simultaneous activities, such as using the mobile phone or the telephone

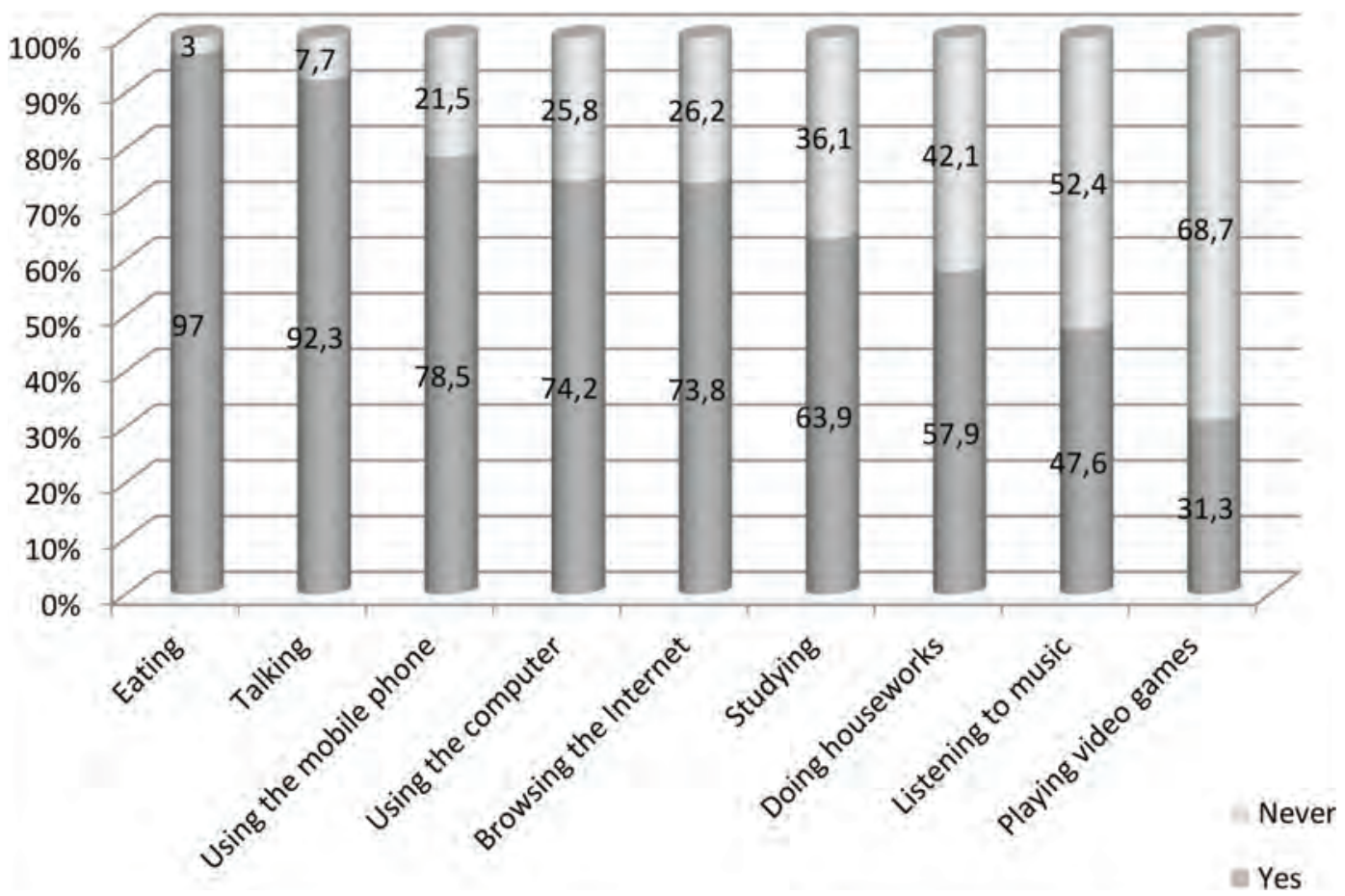

Figure 1: Activities simultaneous to watching television. 
and studying while they watched television. Moreover, during the focus groups several adolescents claimed that they could split their attention between television and other media, such as the mobile phone or the Internet, without being distracted from watching, especially during the advertising breaks.

\section{DISCUSSION}

The MUS allowed us to identify the main features of current leisure preferences and media uses of Catalan adolescents related to the mobile phone, the Internet and television, and to reach the specific objectives stated in the introduction. Regarding the first objective, we found that the adolescents in our sample tended to have quite varied leisure preferences with respect to which we can highlight two key elements: the importance of sharing time with the peer group and the presence of media and ICT, particularly the Internet. In fact, socializing was their first leisure choice, and they generally spent their free time with their friends. This result is consistent with previous studies carried out in Spain and in other countries (e.g. Coatsworth et al. 2005; Ramírez de la Piscina et al. 2006; Roberts and Foehr 2008). However, media still have an important weight in adolescents' leisure time, both in terms of mediarelated activities and media availability. On the one hand, adolescents in our sample carried out several media-related activities in their leisure time, such as browsing the Internet, listening to music or watching television, among others. Also, they had at their disposal multiple media devices at home, both in domestic common spaces and in their personal areas. Nevertheless, we need to differentiate their domestic media equipment, characterized by the presence of a large variety of media devices and the centrality of the television set, from their private media environment, where everything revolves around the computer connected to the Internet. Access to the Internet allows them to maintain a 'bedroom culture' (Livingstone and Bovill 2001), to be connected to their peer group and to consume several audio-visual contents available online, while they remain in their personal 'media oasis' (Zanker and Leander 2006). It is especially remarkable that these features were common to both genders and the three age groups analysed. Moreover, we can distinguish between devices intended for family use and normally located in the shared spaces of the house (e.g., landline or the television set), and those specifically destined for young people's personal use, which were often placed in their own bedrooms or areas (e.g., mobile phone or laptop). In particular, the lack of such media variety in adolescents' personal spaces indicates that the use of some media (i.e. the television set) was still linked to family consumption, as pointed out by previous studies (Adriaens et al. 2011; Holloway and Green 2008; Kortii 2011). Despite this, especially in the qualitative phase, we found that they often did not need a television set in their bedroom because they could use the main one almost at any time, or they could access media contents through the computer and the Internet, for instance YouTube videos. Furthermore, the differences between household and bedroom media equipment can be interpreted as a sign of the different uses that adolescents made of media compared to the rest of the family.

Regarding the second objective, we must highlight that different media answer to different needs, that is, young people in our sample assigned different uses to different media devices. In particular, new media, such as the Internet and mobile phones, especially developed social functions related to the peer group, while television use was more related to family consumption and to entertainment functions. 
As for the new media analysed, first it is worth noting the ubiquity of mobile phones among young people in our sample. Adolescents' use of this device was especially relational, since they used it mainly for calling friends and sending or receiving SMS, as pointed out also in other studies (IBBT 2011). Despite this, we can also foresee indications of new television consumption habits through the mobile phone, since almost 10 per cent of our sample watched television programmes on this device. As pointed out above, this aspect of young people's cross-media consumption needs to be investigated further, especially in relation to smartphones.

Second, the central role of computer and the Internet as communication tools for socializing with others, especially within the peer group, must be emphasized. In fact, young people in our sample especially used the Internet for chatting, e-mailing and sharing contents. Furthermore, the consumption of television contents through the Internet was secondary to the communication activities mentioned above, even if, during the qualitative phase of the research, participants acknowledged viewing television contents on the Internet. The relational use given to the Internet is indeed closely related to the identity building process of adolescence. In fact, the peer group is a main socializing agent during this life period, so adolescents usually concentrate their attention on socializing, an activity that the Internet facilitates more than traditional media such as television.

The teenagers in our sample still spent quite a lot time watching television, and they usually did so in shared domestic spaces, and often in the company of other family members. Therefore, they often had to reach agreements with other family members about what to watch, although they generally acknowledged that they had enough freedom in selecting television programmes, among which they usually preferred fiction programmes and info shows. Thus, television consumption through its traditional support, the television set, remains an important recreational activity for teenagers, as it was practiced by the vast majority of our participants; although the time spent watching television was lower than the time spent online. These findings are consistent with previous studies (Bell and Dittmar 2011; Eurobarometer 2013; Livingstone et al. 2011). Regarding the third objective, our results show evidence of certain similarities between Catalan adolescents in our sample and young people from other western countries, including other regions of Spain. In fact, as in previous studies, we also found that the peer group played a defining role in young people's recreational activities, as spending time with friends was precisely the leisure activity they pursued more often. At the same time, electronic media played an important role in teenagers' leisure time and relational activities, with results consistent with those of previous studies presented above (e.g. Athenstaedt et al. 2009; EGM Baròmetre 2014; Bell and Dittmar 2011; Coatsworth et al. 2005; Fernández-Planells and FiguerasMaz 2012; Funes 2008; Holloway and Green 2008; Livingstone et al. 2011; Roberts and Foehr 2008; Romer et al. 2012; Videnović et al. 2010). In particular, the computer connected to the Internet represents the pillar of teenagers' personal media equipment. The Internet has a central place in adolescents' leisure and media habits: it is not only used to interact with friends, but also to seek information, to create and share contents and to consume audio-visual products to which they have no access through traditional media. So we can say that independently from media availability or time spent with media, adolescents from different contexts can attribute similar functions to media, e.g. socializing with the peer group through new media and relaxing within 
the family context through television. Finally, we did not find any significant differences between genders in their socializing-related leisure activities or time spent with media, as indicated by most previous research. On the other hand, we did find some differences in how girls and boys use media for socializing. In fact, girls in our sample tended to use media for socializing more than boys, both in the case of the mobile phone and the Internet (e.g., for calling friends or sharing contents), and in the case of television watching, since they usually practiced more simultaneous socializing-related activities than boys (e.g. talking).

Regarding the fourth objective, from a media research perspective our study shows an image of teenagers who are used to integrating multiple media in their everyday lives and especially in their free time. Additionally, they often make an active and multitasking use of those media, as in the case of television viewing, confirming a tendency highlighted by previous studies (e.g., Brasel and Gips 2011; Jordan et al. 2007). Also a certain complementarity between different media or devices must be noted, as teenagers attribute communicative and relational functions to new media while maintaining a type of television consumption primarily related to the traditional television set, domestic shared areas and the company of relatives.

Furthermore, our study highlights a certain tendency of teenagers in our sample to integrate media into their leisure activities, especially for socializing purposes. In fact, their use of new media, especially the Internet and the mobile phone, was primarily relational, because it was strongly linked to the maintenance of relations with the peer group, particularly through chat (Internet) or SMS (mobile phone).

\section{CONCLUSIONS}

The general picture of Catalan adolescents emerging from our study is one of active users who especially seek socialization through media uses and leisure activities, that is, who show age-typical behaviour.

However, our study does have some drawbacks. First, it did not count on a representative sample of the Catalan population, so its results cannot be generalized to the whole population, even if they are consistent with previous research and identify some media and leisure tendencies in Catalan youth. In particular, data were obtained in an urban environment, so further studies from other Catalan areas need to be carried out. Besides, it has to be taken into account that the MUS was a part of a wider research project focused on adolescents' consumption of television fiction programmes. For this reason, the MUS did not go deeper in some aspects of leisure preferences and media usage, especially in the qualitative phase, more specifically focused on television fiction consumption. For example, it was not possible to analyse other traditional media, such as radio or the press. Third, it was not possible to measure or properly differentiate between foreground and background activities simultaneous to media consumption. Fourth, the rapid evolution of technology makes it necessary to constantly update media consumption studies, especially those related to young people's habits.

In this regard, further research is needed to go deeper into adolescents' media habits in order to analyse multimedia or cross-media consumption as primary, secondary or tertiary activities. Also, it is necessary to investigate adolescents' use of new devices available, such as smartphones, in relation to both their leisure and media habits, since these devices open brand-new 
possibilities to users and specifically to adolescents, both for communicating activities and for consumption of audio-visual contents. Furthermore, there is a need for qualitative studies, based on in-depth interviews or daily leisure and media diaries that could delve into adolescents' motivations and meanings attributed to media and leisure activities. Finally, comparative studies from different countries could highlight new global tendencies in adolescents' media habits and preferences.

As pioneers in the use of the digital media, today's teenagers are expected to increase their multimedia and multitasking behaviour. Nonetheless, evidence from academic studies indicates that the current young generations still give primary importance to the peer group and socialization, which is the pillar of their identity building process. To do so, they can take advantage of the multimedia changing environment they live in. Thus, future studies will need to delve into what we could call the 'digital socialization process', that is, all current forms of socializing-related activities that adolescents can carry out through new media applications, such as blogs, forums, social networks or smartphone applications.

\section{ACKNOWLEDGEMENTS}

The authors especially thank Robert Lee Bailey for reviewing. The study was supported by the Spanish Ministry of Education and Scienceunder the Project 'Estudio de la programación de la TV digital: innovación en contenidos, formatos y técnicas de programación en la TDT(I+D)' (SEJ2006-10067); the Comissionat per a Universitats i Recerca del Departament d'Innovació, Universitat $i$ Empresa de la Generalitat de Catalunya and the European Social Foundunder GrantFI2008.

\section{REFERENCES}

Adriaens, F., Van Damme, E. and Courtois, C. (2011), 'The spatial and social context of television-viewing adolescents', Poetics, 39: 3, pp. 205-27.

Aierbe, A. and Medrano-Samaniego, C. (2008), 'Usos televisivos de los adolescentes y su relación con los valores'/'Adolescents' television viewing habits and its relation with values', Comunicar, 31: XVI, pp. 109-44.

Arnett, J. J., Larson, R. and Offer, D. (1995), 'Beyond effects: Adolescents as active media users', Journal of Youth and Adolescence, 24: 5, pp. 511-18.

Athenstaedt, U., Mikula, G. and Bredt, C. (2009), 'Gender role self-concept and leisure activities of adolescents', Sex Roles, 60: 5-6, pp. 399-409.

Bauman, Z. (1997), Postmodernity and its Discontents, Cambridge: Polity.

Bell, B. T. and Dittmar, H. (2011), 'Does media type matter? The role of identification in adolescent girls' media consumption and the impact of different thin-ideal media on body image', Sex Roles, 65: 7-8, pp. 478-90.

Brasel, S. A. and Gips, J. (2011), 'Media multitasking behavior: Concurrent television and computer usage', Cyberpsychology, Behavior, and Social Networking, 14: 9, pp. 527-34.

Carlsson, U. and von Feilitzen, C. (eds) (2006), In the Service of Young People? Studies and Reflections on Media in the Digital Age, Götenborg: Götenborg University.

Coatsworth, J. D., Sharp, E. H., Palen, L. A., Darling, N., Cumsille, P. and Marta, E. (2005), 'Exploring adolescent self-defining leisure activities and identity experiences across three countries', International Journal of Behavioral Development, 29: 5, pp. 361-70. 
Drotner, K. (2000), 'Difference and diversity: Trends in young Danes' media use', Media, Culture $\mathcal{E}$ Society, 22: 2, pp. 149-66.

EGM Baròmetre (2014), 'Resum 1a onada 2014', http://www.fundacc.org/ docroot/fundacc/pdf/Resum_1a_onada_2014.pdf.

Ekström, K. M. and Tufte, B. (eds) (2007), Children, Media and Consumption. On the Front Edge, Göteborg: Göteborg University.

Escardibul, J. O., Mora, T. and Villaroya, A. (2013), 'Peer effects on youth screen media consumption in Catalonia (Spain)', Journal of Cultural Economics, 37: 2, pp. 185-201.

Estudio General de Medios (2007), Resumen general, Madrid: AIMC.

Eurobarometer (2013), 'Media use in the European Union', http://ec.europa. eu/public_opinion/archives/eb/eb80/eb80_media_en.pdf.

Fedele, M., García-Muñoz, N. and Prado, E. (2014), 'Adolescents, consum televisiu I control parental. Indicacions a educadors i programadors des d'un estudi sobre el consum adolescent de la ficció televisiva realitzat a Catalunya', Quaderns del CAC, 20, pp. 5-13.

Fernández-Planells, A. and Figueras-Maz, M. (2012), ‘La televisión e Internet hoy: diferentes roles. Usos y consumos en el tiempo libre de jóvenes de Barcelona y Lima', Icono 14, 10: 3, pp. 176-201.

Fiske, J. (1987), Television Culture, London, etc.: Methuen.

Flammer, A. and Schaffner, B. (2003), 'Adolescent leisure across European nations', New Directions for Child and Adolescent Development, 99, pp. 65-68.

Funes, M. J. (2008), 'Cultura, Política y Sociedad', in INJUVE (ed.), Informe de la Juventud en España, Madrid: Gobierno de España, Tomo 4.

Grimley, M. and Allan, M. (2010), 'Towards a pre-teen of digital medial', Australian Journal of Education Technology, 26: 5, pp. 571-84.

Hagen, I. (2007), "“We can't just sit the whole day watching TV": Negotiations concerning media use among youngsters and their parents', Young, 15: 4, pp. 369-93.

Hall, S. (1999), 'Encoding, decoding', in S. During (ed.), The Cultural Studies Reader, 2nd ed., London and New York: Routledge.

Hill, J. A. (2011), 'Endangered childhoods: How consumerism is impacting child and youth identity', Media Culture Society, 33: 3, pp. 347-62.

Holloway, D. and Green, L. (2008), 'Room to view: Family television use in the Australian context', Television \& New Media, 9: 1, pp. 47-61.

IBBT (2011), 'Digimeter. Report 4', http://www.digimeter.be/files/DigimeterReport-4-Web.pdf. Accessed 30 October 2014.

INE (2012), 'Demografía y población', http://www.ine.es/. Accessed 3 February 2014.

Jordan, A., Trentacoste, N., Henderson, V., Manganello, J. and Fishbein, M. (2007), 'Measuring the time teens spend with media: Challenges and opportunities', Media Psychology, 9: 1, pp. 19-41.

Katz, E., Blumler, J. G. and Gurevitch, M. (1974), 'Uses and gratifications research', The Public Opinion Quarterly, 37: 4, pp. 509-23.

Kortii, J. (2011), 'Multidimensional social history of television: Social uses of Finnish television from the 1950s to the 2000s', Television \& New Media, 12: 4, pp. 293-313.

Larson, R. and Seepersad, S. (2003), 'Adolescents' leisure time in the United States: Partying, sports, and the American experiment', New Directions for Child and Adolescent Development, 99, pp. 3-64.

Lee, L. (2005), 'Young people and the Internet: From theory to practice', Young, 13: 4, pp. 15-326. 
Livingstone, S. (2009), 'Half a century of television in the lives of our children', The ANNALS of the American Academy of Political and Social Science, 625: 1, pp. 151-63.

Livingstone, S. and Bovill, M. (eds) (2001), Children and their Changing Media Environment. A European Comparative Study, Mahwah, New Jersey and London: Lawrence Erlbaum Associates Publishers.

Livingstone, S. and Helsper, E. (2007), 'Gradations in digital inclusion: Children, young people and the digital divide', New Media and Society, 9: 4, pp. 671-96.

Livingstone, S. Haddon, L., Gorzig, A., Ólafsson, K., with members of the EU Kids Online Network (2011), 'EU Kids Online. Final Report', http:// www2.1se.ac.uk/media@1se/research/EUKidsOnline/EU\%20Kids\%20 II\%20\%282009-11\%29/EUKidsOnlineIIReports/Final\%20report.pdf.

Lull, J. (1980), 'The social uses of television', Human Communication Research, 6: 3, pp. 197-209.

Maira, S. and Soep, E. (2004), 'United States of adolescence? Reconsidering US youth culture studies', Young, 12: 3, pp. 245-69.

Martín-Guart, R. F. and Fernández-Cavia, J. (2012), 'La digitalización como eje de transformación de las agencias de medios españolas', Pensar la publicidad, 6: 2, pp. 427-45.

McQuail, D. (1997), Audience Analysis, Thousand Oaks, etc.: Sage.

McQuail, D., et al. (1972), 'The television audience: A revised perspective', in D. McQuail (ed.), Sociology of Mass Communication, Middlesex, England: Penguin.

Montero-Rivero, Y. (2005), 'Estudio empírico sobre el serial juvenil «Al salir de clase»: sobre la transmisión de valores a los adolescentes'/'Empirical study on the teensoap «Al salir de clase»: Soap opera's power in the transmission of values among teenagers', Comunicar, 25.

Morley, D. (1986), Family Television: Cultural Power and Domestic Leisure, London: Comedia Pub. Group.

Pascoe, C. J. (2011), 'Resource and risk: Youth sexuality and new media use', Sexuality Research and Social Policy, 8: 1, pp. 5-17.

Pindado, J. (2006), 'Los medios de comunicación y la construcción de la identidad adolescente'/'The mass media and the construction of adolescent identity', Zer, 21, pp. 11-22.

Prado, E., Delgado, M. and García-Muñoz, N. (2012), 'Advertising insertions and television programming in Europe: compared study and typological proposal', ECREA 2012, 4th European Communication Conference, 24-27 October 2012, Istanbul, Turkey.

Ramírez de la Piscina, T., Zarandona, E., Basterretxea, J.I. and Idoiaga, P.(2006), 'Estudio sobre la alfabetización audiovisual de los adolescentes vascos: Recopilatorio de actitudes críticas y acríticas'/'Study of the audiovisual literacy of Basque adolescents: Compilation of critical and uncritical attitudes', Zer, 21, pp. 177-202.

Roberts, D. F. and Foehr, U. G. (2008), 'Trends in media use', The Future of Children, 18: 1, pp. 11-37.

Romer, D., Jameson, K. H. and Pasek, J. (2012), 'Building social capital in young people: The role of mass media and life outlook', Political Communication, 26: 1 , pp. 65-83.

Sabes-Turmo, F. (2005), 'La televisión que quieren los jóvenes: hacia un medio de proximidad'/'The television that youngers want: To a media of proximity', Comunicar, 25. 
Serracant, P. (2012), 'Changing youth? Continuities and ruptures in transitions into adulthood among Catalan young people', Journal of Youth Studies, 15: 2, pp. 161-76.

Silverstone, R. (1994), Television and Everyday Life, London and New York: Routledge.

Spigel, L. and Olsson, J. (2004), Television after TV: Essays on a Medium in Transition, Durham, NC: Duke University Press.

Thulin, E. and Vilhelmson, B. (2007), 'Mobiles everywhere: Youth, the mobile phone, and changes in everyday practice', Young, 15: 3, pp. 235-53.

UNICEF, http://www.unicef.org/adolescence, 14 December 2010.

Vanderwater, E. A. and Lee, S. (2009), 'Measuring children's media use in the digital age: Issues and challenges', American Behavioral Scientist, 52: 8, pp. 1152-76.

Videnović, M., Pešić, J. and Plut, D. (2010), 'Young people's leisure time: Gender differences', Psihologija, 43: 2, pp. 199-214.

Wilska, T. and Pedrozo, S. (2007), 'New technology and young people's consumer identities: A comparative study between Finland and Brazil', Young, 15: 4, pp. 343-68.

Zanker, R. and Lealand, G. (2006), 'Dream worlds and media worlds: Using drawings for insights into the lives of New Zealand children', in U. Carlsson (ed.), In the Service of Young People? Studies and Reflections on Media in the Digital Age, The Clearing House on Children, Youth and Media, Gótenborg: Götenborg University.

\section{SUGGESTED CITATION}

Fedele, M., García-Muñoz, N. and Prado, E. (2015), 'Catalan adolescents' media uses and leisure preferences related to new media and television', Catalan Journal of Communication \& Cultural Studies 7: 1, pp. 51-70, doi: 10.1386/cjcs.7.1.51_1

\section{CONTRIBUTOR DETAILS}

Maddalena Fedele is postdoctoral researcher at the Department of Communication of Universitat Pompeu Fabra, member of CAS Research Group and GRISS Research Group, B.A. from University of Salerno, M.A. from Universitat Pompeu Fabra and Universitat Autònoma de Barcelona and Ph.D. from Universitat Autònoma de Barcelona. Her Ph.D. dissertation consisted of an audience study about teenagers' consumption of TV fiction programmes, and has been awarded the XXIV communication award by CAC (Catalan Audiovisual Council). She has been a collaborating lecturer at the Polytechnic University of Catalonia (UPC) and a visiting researcher at Victoria University of Wellington (New Zealand) and at Glyndwr University (UK). Her research fields are young audiences, TV fiction programmes, and gender \& media.

Contact: GRISS Research Group, Department of Audiovisual Communication and Advertising, Universitat Autònoma de Barcelona, Edifici I. Campus de la UAB, 08193, Bellaterra, Spain.

E-mail: maddalena.fedele@gmail.com

Núria García-Muñoz is Lecturer in Audiovisual Communication and Advertising at the Universitat Autònoma de Barcelona. She has Ph.D. in 
Audiovisual Communication from the Autonomous University of Barcelona. She is member of EUROMONITOR research team and GRISS Research Group. She collaborated with the Faculty of Communication Science at the Italian University of Switzerland and worked as a journalist at the Spanish public television (Televisión Española). She has carried out research projects about media literacy and gender representation in mass media. Her research areas focus on models of television programming and media reception studies, with special attention to child and teenage audience.

Contact: GRISS Research Group, Department of Audiovisual Communication and Advertising, Universitat Autònoma de Barcelona, Edifici I. Campus de la UAB, 08193, Bellaterra, Spain.

E-mail: nuria.garcia@uab.cat

Emili Prado is Professor in Audiovisual Communication and Advertising at Universitat Autònoma de Barcelona, director of GRISS Research Group, of EUROMONITOR and USAMONITOR, and president of the Möbius Barcelona Multimedia prize. He has been Dean of the Faculty of Communication Sciences at the UAB and the Faculty of Information Sciences at the Universidade de Santiago de Compostela. He has also been guest professor and researcher at New York University, University of Québec in Montréal, University of California, Berkeley, New York University, University of Pisa, University of São Paulo, Universidad Adolfo Ibañez in Santiago de Chile, University Leonardo Davinci in Paris, University of Bordeux and several Spanish universities. Advisor of different administrations, companies and regulatory authorities, he is author of different texts about Radio, Television and Information and Communication Technologies. Between 1973 and 1986, he developed his professional career in radio, television and the press.

Contact: GRISS Research Group, Department of Audiovisual Communication and Advertising, Universitat Autònoma de Barcelona, Edifici I. Campus de la UAB, 08193, Bellaterra, Spain.

E-mail: emili.prado@uab.cat

Maddalena Fedele, Núria García-Muñoz and Emili Prado have asserted their right under the Copyright, Designs and Patents Act, 1988, to be identified as the authors of this work in the format that was submitted to Intellect Ltd. 